\title{
Criação de valor compartilhado na educação superior em saúde
}

\section{Created shared value in health higher education}

\author{
HAROLDO DE SÁ MEDEIROS* \\ ABÍLIO PEIXOTO DIÓGENES** \\ LUCIANA BARROSO DE ARRUDA STUDART*** \\ SÉRGIO HENRIQUE ARRUDA CAVALCANTE FORTE****
}

\section{RESUMO}

O objetivo deste artigo é avaliar comparativamente a criação e compartilhamento de valor das Instituições de Ensino Superior (IES), por meio dos atendimentos na área de saúde, considerando suas naturezas pública e privada. Foram realizados dois estudos de caso mediante o uso de procedimentos qualitativos. No primeiro nível de Criação de Valor Compartilhado (CSV), reavaliação de produtos e serviços, apenas a etapa de identificação das questões alvo foi atendida plenamente pelas duas IES. Os resultados do segundo nível, cadeia de valor, possuem avaliações mais homogêneas entre as IES quando comparados aos outros níveis. O suporte ao desenvolvimento de clusters locais, terceiro nível, compreende o apoio dado ao fomento do empreendedorismo local e estímulo ao desenvolvimento da economialocal por meio de um mercado justo. Os resultados mostram a universidade privada atendendo aos níveis e etapas

* Universidade Federal de Rondônia. Aluno do doutorado em Administração de Empresas da Universidade de Fortaleza. Professor do curso de Administração na Universidade Federal de Rondônia, campus de Guajará-mirim. haroldo_sm@hotmail.com .

** Universidade de Fortaleza. Mestre em Administração de Empresas pela Universidade de Fortaleza. abiliodiogenesjr@gmail.com .

*** Universidade de Fortaleza. Mestra em Administração de Empresas pela Universidade de Fortaleza. ls.lifecoaching@gmail.com .

**** Universidade de Fortaleza. Professor do programa de mestrado e doutorado em Administração de Empresas da Universidade de Fortaleza. sergioforte@unifor.br . 
de CSV, enquanto a universidade pública não se fundamenta sequer nos conceitos de Responsabilidade Social Corporativa. A liberdade do gerenciamento privado se mostrou veiculadora de criação e compartilhamento de valor.

Palavras-chave:Criação de valor compartilhado.Instituições de Ensino Superior.Saúde.

\section{Abstract}

This article aims to comparatively evaluate the value creation and sharing in Higher Education Institutions (IES) through health care considering their public and private nature. Two case studies were analyzed using qualitative methodological procedures. In the first level of Creating Shred Value (CSV), reassessment of products and services, only the stage of identifying targets issues was fully done by the two IES. The results of the second level, value chain, have more homogeneous evaluations among IES when compared to the other levels. Support for the development of local clusters, the third level, includes the support given to fostering local entrepreneurship and stimulating the development of the local economy through a fair market. The results show the private university attending to the levels and stages of CSV, while the public university is not based even on the concepts of Corporate Social Responsibility. The freedom of private management proved to be the vehicle for creating and sharing value.

Keywords: Creating shared value.Higher Education Institutions. Health.

\section{INTRODUÇÃo}

As organizações têm adotado diversas estratégias socialmente responsáveis para contribuir na consolidação de seus objetivos. Entretanto, tais estratégias ainda residem na crença de que é necessário separar a atuação empresarial voltada aos negócios, das ações sociais, limitando a distribuição de riqueza na sociedade e ampliando o desenvolvimento irregular do sistema capitalista (PORTER; KRAMER, 2006; PORTER; KRAMER, 2011).

No intuito de conhecer meios que minimizem os efeitos por este desenvolvimento, a Responsabilidade Social Corporativa (em inglês Corporate Social Responsibility-CSR) tem sido amplamente pesquisada, 
caracterizando-se pelo fato de não estreitar a relação entre as ações sociais e o core business organizacional, em que o atendimento às demandas sociais não é incorporado às estratégias das empresas ou, ainda, a adição de valor aos produtos e serviços ofertados à imagem organizacional continuam voltados às obras de filantropia ou mesmo à caridade (PORTER; KRAMER, 2011).

Por outro lado, alguns tipos de organização têm suas ações diretamente voltadas ao atendimento da sociedade, como hospitais, escolas e universidades, ou como registram Filenga e Vieira (2015), até cooperativas. Todavia, mesmo quando há uma aproximação entre o serviço prestado e potenciais benefícios sociais, a atividade principal desses tipos de organizações apresenta limitações para atender às reais necessidades da sociedade, ofertando serviços que restringem seus efeitos em decorrência de pressões institucionais ou deficiências operacionais.

Ao perceber a necessidade de gerar um realinhamento das práticas organizacionais às reais necessidades da sociedade, Porter e Kramer (2011) desenvolveram uma nova perspectiva teórica denominada Criação de Valor Compartilhado (CSV), partindo da premissa que existe dependência mútua entre empresas e sociedade, pois as próprias ações das firmas podem causar danos sociais e podem implicar no aumento de custos para as corporações (CAMILLERI, 2012; PITTS, 2014; PORTER; KRAMER, 2011). Portanto, a CSV tem o foco na forma como há o compartilhamento do valor criado para diferentes stakeholders, sem deixar de incluir elementos de competitividade, comuns ao desenvolvimento econômico empresarial (ARAVOSSIS; PAVLOPOULOU, 2013; SPITZECK; CHAPMAN, 2012). Esta modificação de orientação se consolidou como uma evolução da CSR, sendo abordada pela primeira vez por Porter e Kramer (2006).

Estendendo a ideia de relação e dependência entre organizações e sociedade, as áreas da saúde e educação das universidades se destacam pelo comportamento ativo, transformando a realidade educacional em um ambiente aberto às vivências. $\mathrm{O}$ atendimento promovido por departamentos de saúde às comunidades locais pode se caracterizar como um caso que conseguiu alinhar o atendimento entre demandas sociais e estratégias de negócios, pois ao incluir o alunado à condição de cidadãos, há sua transformação em um cliente 
da universidade que tem a sociedade como cliente maior (CAMPOS et al., 2009). Este tipo de ambiente cria um clima organizacional favorável à geração de criatividade, ao auto treinamento, ao autoconhecimento e à busca pela capacitação no contexto do trabalho (MAIA et al., 2008). Sendo assim, este artigo utiliza como objeto de estudo a CSV, tendo como locus de pesquisa duas universidades, sendo uma pública e a outra privada.

A escolha por um ambiente de pesquisa público e privado se dá pela possibilidade de comparação entre dois ambientes organizacionais com naturezas distintas, mas que possuem finalidades sociais similares. Isso torna possível a ampliação da visão sobre o objeto de estudo ao abranger duas realidades da área de educação e saúde, buscando-se responder ao seguinte questionamento: Como as Instituições de Ensino Superior (IES) criam e compartilham valor para seus stakeholders por meio dos atendimentos de saúde? A fim de responder à questão de pesquisa, o objetivo consiste em avaliar comparativamente a criação e compartilhamento de valor das IES, por meio dos atendimentos na área de saúde, considerando suas naturezas pública e privada.

Existem muitas lacunas conceituais a serem preenchidas no que diz respeito à CSV. Embora uma parte da existência destas lacunas resida no fato de que sua definição é recente, outra parte tem origem na própria concepção. É comum a ideia de que posicionamento e estratégias são ligados apenas às organizações industriais, negando muitas vezes que outros modelos organizacionais, como as organizações públicas e aquelas ofertantes de serviços, também possuam características similares às industriais. É nesta lacuna que está o foco deste estudo, considerando duas organizações, ofertantes de serviços semelhantes para comunidades similares, porém com naturezas jurídicas distintas. Dessa forma, espera-se contribuir com a forma de pensar em criação e compartilhamento de valor.

\section{DA RESPONSABILIDADE SOCIAL EMPRESARIAL À CRIAÇÃo DE VALOR COMPARTILHADO}

A sociedade demonstra insatisfação quanto às ações do setor privado. Tal insatisfação se fundamenta na perspectiva predatória das empresas ao lidar com seus negócios, causando danos sociais 
e econômicos por meio das suas formas de produção e distribuição de produtos e serviços. Parte da responsabilidade por esta relação negativa também reside na atuação governamental, que tenta minimizar as falhas sociais dando ênfase à longevidade dos negócios (PITTS, 2014; PORTER; KRAMER, 2011). A responsabilidade governamental em priorizar os negócios se manifesta na própria ineficiência pública em atender aos seus objetivos, pois o Estado direciona demandas socioambientais às organizações privadas, atribuindo-as tarefas que não se relacionam às suas atividades fins (LOMBARDO; D'ORIO, 2012).

Diante deste cenário negativo entre sociedade e empresas, originado pela dinâmica produtivista do sistema capitalista, a CSV surge como uma perspectiva teórica que tem como foco o realinhamento entre necessidades da sociedade e estratégias organizacionais, infligindo uma nova concepção de capitalismo. Distinto da CSR e da filantropia, a CSV amplia as ações empresariais voltadas à dimensão social para o nível estratégico das organizações. Deste modo, entende-se CSV como o conjunto de políticas e práticas operacionais que aumentam a competitividade de uma empresa, enquanto esta contribui simultaneamente para o avanço de condições econômicas e sociais nas comunidades em que atua, ampliando as conexões entre a sociedade e progresso econômico (PORTER; KRAMER, 2011).

Defendida como uma evolução do conceito da CSR (CRANE et al., 2014; MEDEIROS et al., 2016; PORTER; KRAMER, 2006; WÓJCIK, 2016), a CSV abrange dois aspectos, sendo o primeiro o aumento da competitividade e o segundo a geração de valor para a sociedade por meio do atendimento das suas necessidades (SPITZECK; CHAPMAN, 2012). Dessa forma, a CSV tem como foco identificar e evitar externalidades a fim de maximizar retorno sobre capital investido pelos acionistas das empresas, garantindo, ao mesmo tempo, benefícios para outros stakeholders (ARAVOSSIS; PAVLOPOULOU, 2013).

A CSV poderia substituir a CSR para orientar os investimentos das empresas em suas comunidades. Os programas de CSR focam principalmente na reputação das empresas e tem uma pequena conexão com o negócio, sendo difícil de ser justificado e mantido em longo prazo. Em contraste, a CSV está integrada à rentabilidade das empresas e à posição competitiva (PORTER; KRAMER, 2011), conforme disposto no Quadro1. 


\section{Quadro 1- Diferenças entre CSR e CSV}

\begin{tabular}{|l|l|}
\hline $\begin{array}{l}\text { Responsabilidade Social } \\
\text { Empresarial }\end{array}$ & Criação de Valor Compartilhado \\
\hline Valor: realização de boas ações. & $\begin{array}{l}\text { Valor: Benefícios econômicos e sociais } \\
\text { em relação ao custo. }\end{array}$ \\
\hline $\begin{array}{l}\text { Cidadania, filantropia e } \\
\text { sustentabilidade. }\end{array}$ & $\begin{array}{l}\text { Desenvolvimento de valor } \\
\text { conjunto com a sociedade e a empresa. }\end{array}$ \\
\hline $\begin{array}{l}\text { Resposta a pressões sociais } \\
\text { externas. }\end{array}$ & $\begin{array}{l}\text { Parte integrante das estratégias } \\
\text { competitivas. }\end{array}$ \\
\hline $\begin{array}{l}\text { Separada da maximização de } \\
\text { lucros. }\end{array}$ & $\begin{array}{l}\text { Tem como um dos objetivos a } \\
\text { maximização de lucros. }\end{array}$ \\
\hline $\begin{array}{l}\text { Agenda definida por relatórios } \\
\text { externos e preferências pessoais. }\end{array}$ & $\begin{array}{l}\text { Agenda específica da empresa } \\
\text { internamente gerada. }\end{array}$ \\
\hline $\begin{array}{l}\text { Impacto é delimitado pelo } \\
\text { orçamento destinado ou pela } \\
\text { atividade corporativa. }\end{array}$ & $\begin{array}{l}\text { Realinha todo orçamento da } \\
\text { empresa. }\end{array}$ \\
\hline
\end{tabular}

Fonte: Adaptado pelos autores (2017) a partir de Porter e Kramer (2011)

É importante perceber que a CSV concentra escolhas feitas entre cada parte que deve beneficiar ambos os lados, e não apenas uma das partes interessadas (PITTS, 2014). Nesse sentido, existem três níveis de criação do valor compartilhado: reavaliação dos produtos e mercados; redefinição da produtividade na cadeia de valor e suporte ao desenvolvimento de clusters locais (PORTER et al., 2012; PORTER; KRAMER, 2011), conforme Quadro 2.

A identificação das necessidades da sociedade e sua transformação em oportunidades de negócios já haviam sido descritas por Prahalad e Hart (2002), na qual abordam o desenvolvimento de novos produtos e serviços voltados para mercados com públicos de baixa renda em países em desenvolvimento. Tanto Prahalad e Hart (2002), quanto Porter e Kramer (2011) consideram que o mercado é mutável e que a identificação de necessidades como oportunidades proporcionaria um reposicionamento das empresas em relação aos mercados tradicionais, além disso, poderia favorecer o conhecimento de novos mercados que não eram considerados como promissores. Deste modo, a reavaliação dos produtos e mercados implicaria em uma nova concepção de produtos e formas de distribuição, abrindo espaços para inovações, pois as próprias demandas sociais são mutáveis. 
Quadro 2 - Níveis de criação de valor

\begin{tabular}{|c|c|c|c|}
\hline $\begin{array}{l}\text { Níveis de } \\
\text { criação de } \\
\text { valor }\end{array}$ & Objetivo & $\begin{array}{l}\text { Resultados para } \\
\text { o negócio }\end{array}$ & $\begin{array}{l}\text { Resultados para a } \\
\text { sociedade }\end{array}$ \\
\hline $\begin{array}{l}\text { Reavaliação } \\
\text { dos produ- } \\
\text { tos e merca- } \\
\text { dos }\end{array}$ & $\begin{array}{l}\text { Identificar necessi- } \\
\text { dades da socieda- } \\
\text { de para transformá } \\
\text {-las em oportuni- } \\
\text { dades de negócios, } \\
\text { incorporando seus } \\
\text { aspectos aos pro- } \\
\text { dutos e formas de } \\
\text { distribuição. }\end{array}$ & $\begin{array}{l}\text { Aumento da re- } \\
\text { ceita; incremento } \\
\text { na participação } \\
\text { de mercado e } \\
\text { níveis de cresci- } \\
\text { mento; melhoria } \\
\text { da rentabilidade. }\end{array}$ & $\begin{array}{l}\text { Melhoria na assistên- } \\
\text { cia médica; redução } \\
\text { da emissão de car- } \\
\text { bono; melhoria da } \\
\text { condição nutricional } \\
\text { ou educacional. }\end{array}$ \\
\hline $\begin{array}{l}\text { Redefinição } \\
\text { na cadeia de } \\
\text { valor }\end{array}$ & $\begin{array}{l}\text { Gerenciar me- } \\
\text { lhor as operações } \\
\text { internas, a fim de } \\
\text { aumentar a produ- } \\
\text { tividade e reduzir } \\
\text { riscos. }\end{array}$ & $\begin{array}{l}\text { Aumento de } \\
\text { produtivida- } \\
\text { de; redução de } \\
\text { custos logísticos } \\
\text { e operacionais; } \\
\text { garantia de } \\
\text { fornecimento; } \\
\text { aumento de qua- } \\
\text { lidade; melhoria } \\
\text { da rentabilidade. }\end{array}$ & $\begin{array}{l}\text { Redução do uso } \\
\text { de energia e água; } \\
\text { redução do uso de } \\
\text { insumos; melhoria } \\
\text { das competências e } \\
\text { remuneração da força } \\
\text { de trabalho. }\end{array}$ \\
\hline $\begin{array}{l}\text { Suporte ao } \\
\text { desenvol- } \\
\text { vimento } \\
\text { de clusters } \\
\text { locais }\end{array}$ & $\begin{array}{l}\text { Modificar o am- } \\
\text { biente externo a } \\
\text { organização a fim } \\
\text { de proporcionar } \\
\text { crescimento e gan- } \\
\text { hos de } \\
\text { produtividade. }\end{array}$ & $\begin{array}{l}\text { Redução de } \\
\text { custos; garantia } \\
\text { de fornecimen- } \\
\text { to; melhoria na } \\
\text { infraestrutura de } \\
\text { distribuição; me- } \\
\text { lhoria do acesso } \\
\text { à mão de obra; } \\
\text { melhoria da } \\
\text { rentabilidade. }\end{array}$ & $\begin{array}{l}\text { Incremento da oferta } \\
\text { de trabalho; melhoria } \\
\text { nos serviços educa- } \\
\text { cionais e de saúde; in- } \\
\text { cremento nos ganhos } \\
\text { econômicos. }\end{array}$ \\
\hline
\end{tabular}

Fonte: Adaptado pelos autores (2017) a partir de Porter; Kramer (2011) e Porter et al. (2012). 
A cadeia de valor consiste no conjunto de operações primárias e secundárias que possuem relevância estratégica para a compreensão do comportamento de custos e potenciais recursos de diferenciação para os produtos e serviços (PORTER, 1991). A redefinição da produtividade na cadeia de valor incide no gerenciamento de sete elementos estratégicos: energia, logística, insumos e matéria-prima, formas de compra, distribuição, produtividade dos empregados, localização (PORTER; KRAMER, 2011; PORTER et al., 2012). Todos estes elementos, caso sejam mal gerenciados, podem causar impactos sociais e ambientais negativos. Logo, sob a perspectiva da CSV, a redefinição da produtividade na cadeia de valor teria características ligadas à sustentabilidade, tendo como ideia central ajustes em operações, desde a aquisição de insumos à distribuição dos produtos, que favorecesse economias locais e o fornecimento de matérias-primas de empresas com certificados ambientais. Desta forma, organizações diminuiriam externalidades, incrementando questões ligadas à qualidade dos produtos, eficiência produtiva e reduziriam seus custos oriundos do pagamento de taxas ou multas pela utilização de insumos prejudiciais ao meio ambiente.

O terceiro nível de CSV é o suporte ao desenvolvimento de clusters. É importante destacar que esta perspectiva de interação de empresas com fornecedores locais, fomentando a economia e o desenvolvimento local não é recente (CRANE et al., 2014), havendo o próprio Porter (1998) publicado sobre o assunto. A existência de clusters é fator preponderante para o desenvolvimento de economias regionais, desempenhando a função de estimular a produtividade e eficiência de micro e pequenos produtores, fomentando o empreendedorismo local e a criação de postos de trabalho, inclusive por meio de serviços auxiliares. Destaca-se como aspecto positivo da criação e suporte de clusters a formação de mercados justos e transparentes. Neste tipo de mercado, há garantia da compra de insumos e a confiança no fornecimento, elementos que podem promover a qualidade e eficiência produtiva, bem como aumentar substancialmente a renda e poder de compra da população local (PORTER; KRAMER, 2011).

O princípio de níveis de CSV pode ser compreendido como um conjunto de etapas (PORTER; KRAMER, 2011; PORTER et al., 
2012). Deste modo, o suporte ao desenvolvimento de clusters locais não poderia ser realizado sem a redefinição na cadeia de valor que agregam valor aos produtos, bem como este último não poderia ser feito sem a reavaliação de produtos e mercados. Portanto, não seria possível para uma empresa alcançar um nível sem passar pelo anterior. A identificação de mercados em potencial, levando em conta demandas sociais, levaria a identificação dos possíveis produtos que atenderiam a tais demandas. Posteriormente, questões operacionais ligadas à produção seriam levadas em consideração, mediante avaliação de quais elementos poderiam agregar valor para se tornar vantagem competitiva e proporcionar penetração no mercado pretendido. Após o reconhecimento das questões operacionais, a localização é analisada, ponderando o apoio ao desenvolvimento de conglomerados por meio de incentivos financeiros a fornecedores e populações locais.

Apesar do arcabouço teórico desenvolvido acerca da temática CSV, o conceito apresenta algumas lacunas, ignorando tensões inerentes aos objetivos sociais e econômicos, sendo ingênuo sobre as conformidades entre os desafios do negócio, e é baseado em uma concepção superficial do papel da corporação na sociedade. Apesar de Porter e Kramer possuírem a intenção de surpreender o CSR com a CSV, eles apenas alcançaram uma extensão (BESCHORNER; HADJUK, 2015; CRANE et al., 2014).

Outra contribuição ainda em discussão é a de Rocchi e Ferrero (2014), que é expandir o modelo de análise para sistemática de valor compartilhado integrando o pilar em "desenvolvimento de virtudes pessoais", posto que a teoria original seria um processo que não se aplicaria às pessoas, ou seja, não aborda diretamente os trabalhadores, nem os líderes de processos organizacionais, e apenas fazem referência às atividades sem considerar os agente.

Porém, mesmo que sua concepção teórica seja alvo de críticas em decorrência de suas possíveis lacunas, a CSV surgiu no início da década de 2010 como uma forma de dirimir desigualdades sociais e ambientais sem provocar uma ruptura com o capitalismo, considerado por Porter e Kramer (2011) como um sistema que proporciona conhecimento e atendimento das necessidades sociais, criação de empregos e distribuição de riqueza. 


\subsection{Monitoramento e avaliação de criação de valor compartilhado}

Existe uma consistente preocupação sobre a capacidade de desenvolver uma medição universal única de CSV ou de realizar comparações diretas em diferentes setores (PITTS, 2014). Muitos ainda se questionam se o desempenho social das empresas deve ser medido, porém essa medição se mostra de importância para os negócios e para a sociedade, residindo na elaboração de medidas válidas e confiáveis que realmente podem ser utilizadas em alguma ação gerencial (CARROLL, 2000).

Dado que as ferramentas mais comumente utilizadas para medição de CSV foram desenvolvidas nos Estados Unidos, não é estranho que estudiosos de outras localidades tenham questionado a adequação destas medidas. Ainda, nota-se uma necessidade geral de desenvolver uma medida mais apropriada para avaliar o impacto e que possa ser usada de forma consistente e com confiança, independentemente do contexto ou empresa em que é estudado (PORTER; KRAMER, 2006).

Levando em consideração uma necessidade de identificar a existência ou não de CSV em organizações, a mensuração do valor compartilhado requer um processo interativo que é integrado à estratégia de negócio, não podendo ser única ou periódica e deve estar atrelada à mensuração de desempenho do negócio. A ideia de mensuração da CSV, embora aparentemente tenha uma relação direta com uso de técnicas quantitativas, se apresenta como um modelo qualitativo de avaliação, conforme Figura1. Esta concepção qualitativa se dá pelo fato de não haver uma escala, coeficiente ou qualquer modo de medida que possibilite uma real análise quantitativa do posicionamento organizacional baseado em CSV.

As estratégias e avaliações dispostas no modelo são divididas em quatro etapas. As prioridades estratégicas informam o foco e a extensão de medição do valor compartilhado; os dados e os insights de mensuração do valor compartilhado informam refinamento da estratégia de valor compartilhado. Este ciclo de feedback contínuo é um dos principais benefícios da mensuração do valor compartilhado. Porém, é importante ressaltar que essa avaliação vai depender da 
indústria, da estratégia da empresa, assim como seu modelo de negócio (PORTER et al., 2012).

Primeira etapa: Identificar a questão social alvo. O ponto de partida para o valor compartilhado é identificar e priorizar as questões sociais específicas que representam oportunidades para aumentar a receita ou reduzir custos. Isso requer um rastreio sistemático das necessidades e lacunas sociais não atendidas e uma análise de como elas se sobrepõem ao negócio em todos os três níveis de valor compartilhado. O resultado deste passo é uma lista de questões sociais prioritárias alvo de uma estratégia de valor compartilhado.

Segunda etapa: Fazer o caso do negócio. Depois de identificar o impacto do potencial social em um ou mais dos três níveis de valor compartilhado, o próximo passo é desenvolver um caso de negócio sólido com base em pesquisa e análise de como uma melhoria social pode desenvolver diretamente o desempenho dos negócios. Este passo inclui a identificação dos alvos e especificação das atividades e custos envolvidos para cada oportunidade de valor compartilhado, modelando o potencial de negócios e resultados sociais em relação aos custos (ou seja, o valor potencial de criação), e tomando decisões de ir ou não com cada ação.

Figura 1 - Estratégia integrada de valor compartilhado e mensuração

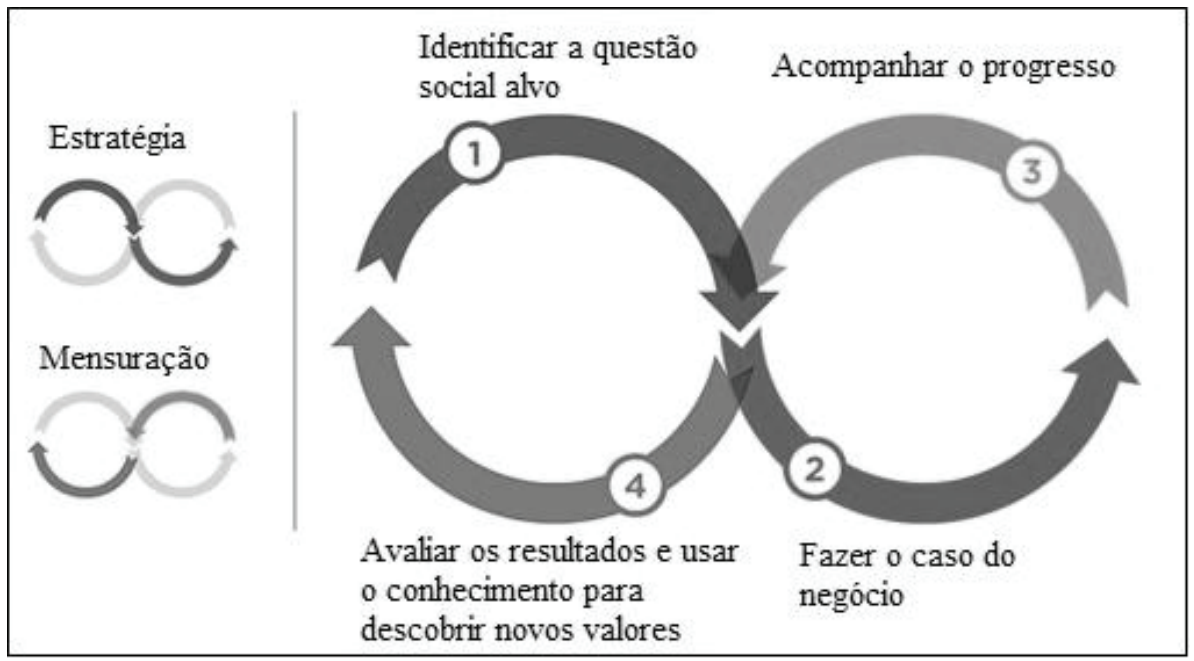

Fonte: Porter et al. (2012). 
Terceira etapa: acompanhar o progresso. Usando o exemplo do negócio como um roteiro, empresas acompanham seu progresso para alcançar os alvos desejados, tal como acontece com qualquer processo de melhoria e desenvolvimento. Esta etapa inclui acompanhar entradas e saídas, bem como o desempenho financeiro em relação às projeções realizadas.

Quarta etapa: avaliar os resultados e usar o conhecimento para descobrir novos valores. A etapa final visa validar a ligação entre o social e os resultados de negócio e determinar se o investimento de recursos corporativos e esforços produzidos geraram um bom retorno comum. Ao concentrar-se em princípios de valor compartilhado, é importante ressaltar que as escolhas realizadas devem beneficiar sociedade e acionistas, pois o prosseguimento de políticas e ações que beneficiem apenas uma das partes em detrimento da outra, pode promover repercussões sociais e ambientais negativas (PITTS, 2014).

\subsection{CSV e CSR na educação e saúde em IES}

A CSV e CSR são desenvolvidas por meio de políticas, rotinas e programas gerenciais que perpassam todos os níveis da organização que as adotam, sistematizando o diálogo com os públicos com quem ela mantém relações. No entanto, a responsabilidade social universitária é concebida como política, ética e de qualidade exercida pela comunidade universitária como um todo. Isso demanda gestão responsável dos impactos educacional, cognitivo e trabalho ambiental das IES, de modo que o diálogo participativo com as coletividades consiga promover o desenvolvimento humano sustentável (MOROSINI, 2008).

Como ocorre no ambiente empresarial, a discussão sobre o papel social ganha destaque nas universidades. Para Drucker (1986), como nossa sociedade está se tornando rapidamente uma sociedade de organizações, todas as instituições terão de fazer com que o atendimento de valores, crenças e propósitos sociais básicos sejam importante objetivo para suas atividades contínuas e não uma responsabilidade social que restrinja ou se situe fora de suas funções fundamentais, enquadrando-se nesse contexto as instituições universitárias.

No Brasil, o Sistema Nacional de Avaliação da Educação Superior (SINAES), trouxe consigo uma interpretação do governo do 
que seria responsabilidade social no ensino superior brasileiro. Seus mecanismos de avaliação têm por objetivo assegurar o processo nacional de avaliação das instituições de educação superior, dos cursos de graduação e do desempenho acadêmico e de seus estudantes (ASHLEY; FERREIRA; REIS, 2006). O art. $3^{\circ}$ da Lei no 10.861/04 estabelece que a avaliação das instituições de educação superior deve ter como objetivo identificar o perfil e o significado de sua atuação, por meio de suas atividades, cursos, programas, projetos e setores, considerando as diferentes dimensões institucionais, dentre elas, obrigatoriamente, a responsabilidade social da instituição, considerando especialmente no que se refere à sua contribuição em relação à inclusão social, ao desenvolvimento econômico e social, à defesa do meio ambiente, da memória cultural, da produção artística e do patrimônio cultural (BRASIL, 2004).

A extensão universitária define-se como dimensão do trabalho desenvolvido pela academia no ensino e na pesquisa, na formação de recursos humanos e na produção e divulgação do conhecimento produzido e não pode ser confundida com assistencialismo. A escola não pode substituir o Estado no atendimento de necessidades básicas da população pobre. É preciso evitar que se continue a confundir extensão universitária com ações filantrópicas baseadas no trabalho voluntário dos alunos, professores e funcionários: a chamada responsabilidade filantrópica (TODOROV, 2005). O trabalho de extensão só se justifica à medida que extensão é ensino e ou pesquisa: o aluno atende à população carente como parte de seu aprendizado prático, seja no exercício profissional, seja no treinamento de suas habilidades de pesquisa. A responsabilidade social está em tudo o que cerca a formação dos alunos e a produção de conhecimento.

A universidade forma o mais alto nível de qualificação do indivíduo, do ponto de vista técnico e científico. Entretanto, nem sempre nela se tem formado o profissional cidadão, comprometido com a mudança almejada pelas sociedades. Tal responsabilidade beneficia tanto as organizações quanto o entorno social em que estão inseridas (VALLAEYS, 2006).

Seguindo com a ideia de que a instituição universitária tem um papel imprescindível de responsabilidade para com as questões sociais, muitas universidades têm procurado alinhar as funções de 
ensino, pesquisa e extensão. Um exemplo pertinente é o que se refere ao papel que vem sendo realizado pelos hospitais universitários frente ao colapso em que se encontra o sistema de saúde brasileiro. Essa situação no sistema de atendimento de saúde, verificada nos últimos anos, fruto do descredenciamento com o governo da maioria dos hospitais privados e filantrópicos, deixou sobre os hospitais públicos, especialmente os universitários, um fardo cujo peso vem aumentando a cada ano. Esses têm "assumido o papel de última e, por vezes, única salvaguarda da imensa população não coberta por seguros de saúde" (MARTINS, 1997, p. 49).

Ao transcender a responsabilidade social, as universidades criam e compartilham valores ao ofertar produtos inovadores que permitam aos estudantes o acesso a diferentes programas educacionais, incluindo questões multidisciplinares. Ainda, tem como importante mecanismo de CSV o desenvolvimento de clusters por meio de alianças entre organizações que fazem parte da comunidade educacional (MENA; ZELAYA, 2013; NIKOLOVA; ANDERSEN, 2017). Essas estratégias de criação e compartilhamento de valor norteiam os serviços das IES estão relacionadas às suas próprias atividades de extensão. Ao estender suas ações às comunidades, formam um ambiente institucional de cooperação, valorizando os demandantes dos serviços ofertados.

\section{Metodologia}

No intuito de alcançar o objetivo proposto no artigo foram desenvolvidos dois estudos de casos por meio de pesquisa qualitativa. Os estudos de casos se caracterizam como um conjunto de técnicas que tem como foco a compreensão de fenômenos contemporâneos inseridos em um contexto da vida real, além disso, têm por objetivos responder perguntas do tipo "como" ou "por que" sem a necessidade de controle sobre eventos comportamentais e possuem fontes múltiplas de evidências (YIN, 2001). Enquanto isso, a pesquisa qualitativa é orientada para a análise de casos concretos em sua particularidade temporal e local, partindo das expressões e atividades das pessoas em seus contextos locais (FLICK, 2004). Justifica-se a caracterização deste estudo pela sua problematização, o uso de mais de uma fonte de evidências, assim como pelo método 
de análise qualitativo e pela contemporaneidade das organizações e eventos estudados.

Os procedimentos metodológicos foram divididos em cinco etapas. Na primeira etapa foi realizada a revisão da literatura, contemplando os conceitos de CSR e CSV, o processo de avaliação e da relação da CSV com o setor de educação em saúde.

A segunda consistiu no levantamento de dados referentes aos casos estudados. Estes dados foram retirados dos sites institucionais, tendo por objetivo ampliar o conhecimento sobre os serviços ofertados pelas organizações.

Na terceira etapa houve a construção e aplicação do roteiro estruturado de entrevista, contendo 15 perguntas que foram feitas para gestores estratégicos (diretores da área de Saúde) de cada organização alvo deste estudo. As entrevistas foram realizadas nos dias 06/07/2015 na IES privada (Caso A), e 21/07/2015 na IES pública estadual (Caso B), tendo como duração 58 minutos e 56 minutos, respectivamente. O conteúdo e a sequência das perguntas do roteiro de entrevistas tiveram como fundamento a relação entre os três níveis e as quatro etapas de CSV, sendo os níveis a Reavaliação dos produtos e mercados - Nível 1; Redefinição na cadeia de valor Nível 2; Suporte ao desenvolvimento de clusters locais - Nível 3, e as etapas a Identificação das questões alvo - Etapa 1; Fazer o caso do negócio - Etapa 2; Acompanhamento do progresso - Etapa 3; Avaliação dos resultados - Etapa 4, conforme Quadro 3. Esta relação se estendeu aos outros procedimentos metodológicos.

A quarta etapa consistiu na análise dos dados. Os procedimentos desta etapa foram baseados na análise de conteúdo, contendo três fases: pré-análise; exploração; tratamento de resultados, inferência e interpretação (BARDIN, 2009). Na pré-análise foram estabelecidas a problemática e objetivo do estudo, bem como a delimitação dos indivíduos pesquisados, considerando quem eram os mais indicados para fornecer informações relevantes, devido às suas funções e tempos de experiências nos cargos exercidos. A codificação dos dados, procedimento correspondente à fase de exploração, ocorreu por meio da disposição dos trechos das entrevistas. O tratamento dos resultados foi realizado mediante transcrição e se deu por meio dos seguintes procedimentos: elaboração de quadro de análise; definição de palavras-chave e alocação das palavras-chave no quadro de análise. 


\begin{tabular}{|c|c|c|}
\hline \multicolumn{3}{|c|}{ Quadro 3 - Relação entre os níveis e as etapas de CSV } \\
\hline $\begin{array}{l}\text { Ní- } \\
\text { veis }\end{array}$ & $\begin{array}{l}\text { Eta- } \\
\text { pas }\end{array}$ & Questões \\
\hline \multirow{4}{*}{1} & 1 & $\begin{array}{l}\text { 1. Há alguma consulta à população local quando algum serviço } \\
\text { é elaborado ou avaliado? 2. Como esta consulta é realizada? }\end{array}$ \\
\hline & 2 & $\begin{array}{l}\text { 3. Como a prestação dos serviços de saúde se constitui como } \\
\text { fonte de vantagem competitiva para a universidade? }\end{array}$ \\
\hline & 3 & $\begin{array}{l}\text { 4. Quais os procedimentos para verificar a eficácia dos serviços } \\
\text { prestados em relação ao atendimento das demandas sociais? }\end{array}$ \\
\hline & 4 & $\begin{array}{l}\text { 5. Caso fossem verificadas mudanças nas necessidades sociais do } \\
\text { público-alvo atendido, como estas seriam levadas em considera- } \\
\text { ção para redefinições dos tipos de serviços prestados? }\end{array}$ \\
\hline \multirow{4}{*}{2} & 1 & $\begin{array}{l}\text { 6. A prestação dos serviços é adequada para o atendimento das } \\
\text { demandas sociais, considerando as características do público } \\
\text {-alvo? 7. Itens como localização e materiais são analisados na } \\
\text { formulação dos serviços prestados? } 8 \text {. Os alunos, professores } \\
\text { ou outros indivíduos prestadores de serviços são instruídos } \\
\text { para atender ao público-alvo, considerando suas características } \\
\text { sociais? }\end{array}$ \\
\hline & 2 & $\begin{array}{l}\text { 9. Existe alguma ação educacional ou algo similar sobre o uso } \\
\text { dos insumos durante a prestação de serviços? (Ex.: uso conscien- } \\
\text { te da água, energia, resíduos, lixo). Se houver, como funciona? }\end{array}$ \\
\hline & 3 & $\begin{array}{l}\text { 10. Os serviços prestados implicam em algum tipo de redução } \\
\text { de custos ou aumento da rentabilidade para a instituição? Quan- } \\
\text { to? }\end{array}$ \\
\hline & 4 & $\begin{array}{l}\text { 11. Como as informações relacionadas às operações são coleta- } \\
\text { das e utilizadas para aperfeiçoar os serviços? }\end{array}$ \\
\hline \multirow{4}{*}{3} & 1 & $\begin{array}{l}\text { 12. Os serviços de saúde se constituem como um meio de pro- } \\
\text { mover o desenvolvimento econômico local? }\end{array}$ \\
\hline & 2 & $\begin{array}{l}\text { 13. Como os serviços prestados favorecem o aprendizado dos } \\
\text { alunos e o desenvolvimento dos colaboradores? }\end{array}$ \\
\hline & 3 & $\begin{array}{l}\text { 14. Como a universidade verifica que seus serviços estão favore- } \\
\text { cendo o desenvolvimento local? }\end{array}$ \\
\hline & 4 & $\begin{array}{l}\text { 15. As informações obtidas durante a execução dos serviços } \\
\text { prestados são utilizadas para redefinição do modo como a uni- } \\
\text { versidade atua? }\end{array}$ \\
\hline
\end{tabular}

Fonte: Adaptado pelos autores (2017) a partir de Porter e Kramer (2011) e Porter et al. (2012). 
Na elaboração do quadro de análise, as palavras-chave foram representadas pelos três níveis e quatro etapas da CSV, considerando a relação disposta anteriormente no Quadro 3. Mediante tratamento dos dados, a inferência e a interpretação foram realizadas permitindo avaliar as organizações quanto suas estratégias eserviços, estando dispostas em formato de análise comparativa. A nomenclatura utilizada para expor os resultados desta avaliação compreende as três legendas: total, parcial e não atendeu, conforme Quadro 4. Estas três legendas foram utilizadas para diferenciar o posicionamento entre as estratégias e serviços das IES estudadas em relação e os níveis e etapas da CSV.

A quinta etapa consistiu na discussão dos resultados de pesquisa com estudos anteriores sobre CSV.

\subsection{Caso A: IES privada}

A IES privada possui um Núcleo Médico de Atenção Integrada (NAMI) que está localizado na cidade de Fortaleza-CE. O núcleo foi criado em 1978, com aproximadamente 3.500 alunos, estando todos engajados em proporcionar uma vivência profissional aos alunos e realização de pesquisas. O núcleo abrange os cursos de graduação em medicina, enfermagem, nutrição, psicologia, fisioterapia, fonoaudiologia, serviço social e terapia ocupacional. Além disso, dispõe de uma academia, espaço não só destinado a práticas esportivas, mas também ao complemento das atividades médicas integradas aos pacientes.

O orçamento das atividades do NAMI tem a seguinte distribuição: $15 \%$ apoiado por uma fundação educacional; $80 \%$ proveniente do Sistema Único de Saúde (SUS); e 5\% de outras fontes de financiamento, correspondentes à utilização de salas por profissionais liberais ou remunerações oriundas de serviços prestados por meio dos planos de saúde.

O NAMI tem como missão desenvolver ações de saúde em nível secundário de atenção, promovendo, prevenindo, diagnosticando, tratando e reabilitando de maneira interdisciplinar, visando à melhoria da qualidade de vida de seus usuários. $\mathrm{O}$ atendimento do núcleo ocorre por meio de consultas médicas, análises laboratoriais, imunizações, diagnósticos por imagem, entre outros serviços 
que envolvem a saúde. A IES privada, por meio do NAMI, está presente em 19 unidades de atendimento a saúde, considerando que existem 21 unidades básicas em Fortaleza, tornando regionalizada a articulação com o SUS. Nem sempre todas as unidades de saúde têm alunos de todos os cursos trabalhando nelas, pois o planejamento tem a função de direcionar os serviços que serão prestados para cada unidade no município.

A consulta à população para o reconhecimento de suas necessidades é feita de forma indireta. A IES privada presta serviços por meio de um contrato com a Secretaria Municipal de Saúde, que define os serviços que necessita com base nas demandas municipais. A identificação das necessidades da população é realizada pela Prefeitura Municipal de Fortaleza (PMF), utilizando as informações coletadas durante os atendimentos do Programa de Saúde da Família (PSF). Além da PMF, há um direcionamento dos serviços conforme demanda estipulada pelo Ministério da Saúde (MS), abrangendo a esfera pública federal. O NAMI é credenciado no MS como centro especializado de reabilitação física, mental, visual e psicológica. Esse tipo de credenciamento implica em normas específicas de monitoramento e avaliação das atividades e dos resultados dos atendimentos.

Os serviços prestados se constituem como fonte de vantagem competitiva pelo fato de que os alunos iniciam a vivência das suas atividades profissionais desde os primeiros semestres, mesmo que na execução de atividades sem complexidade ou apenas como observadores. Além disso, pelo fato da organização dos serviços serem de responsabilidade da própria IES, os alunos possuem uma educação interdisciplinar, não estando sujeitos a um engessamento curricular, mesmo que o direcionamento dos serviços estejaligado às demandas identificadas pela Secretaria Municipal de Saúde.

A verificação da eficácia dos serviços ofertados depende do vínculo organizacional atrelado ao atendimento prestado. Nos casos dos atendimentos realizados em parcerias com a Secretaria Municipal de Saúde e com o MS, a eficácia é avaliada conforme parâmetros definidos por estas organizações públicas. Para os atendimentos realizados nos programas da própria IES, indicadores são preestabelecidos para os resultados, porém, não há avaliação aplicada diretamente com os usuários dos serviços. Entretanto, no 
ano de 2015 está sendo implementada uma nova forma de avaliação, fundamentada no modelo de Avaliação de Kirkpatrick, que abrange os diversos agentes que atuam e usufruem dos serviços de saúde, como alunos, professores e usuários dos serviços. Este modelo de avaliação tem sua aplicação descrita em trabalhos como os de Triviños, Sirhan, Moore e Montero (2011, 2014). Sua avaliação se dá em quatro níveis, permitindo conhecer a motivação e reação dos agentes (alunos e professores): Nível 1 - aprendizagem dos alunos; Nível 2 - transformação da realidade da sociedade mediante atuação organizacional; Nível 3 - mensurando o impacto da presença dos alunos e professores nas comunidades que são atendidas pela IES, mesmo que haja vinculação com a PMF ou com o MS; Nível 4 - avaliar o benefício para a sociedade, aplicando instrumentos de avaliação aos usuários dos serviços. Para atender ao nível 4 da avaliação, algumas medidas estão sendo realizadas, como grupos focais, com o objetivo de construir um instrumento que seja capaz de retratar a percepção dos usuários. A avaliação com os alunos já é realizada, sendo constituídos grupos focais e aplicação de questionários estruturados ao final dos semestres. Este nível de avaliação compreende as disciplinas, os atendimentos e o próprio curso. Além disso, os professores são ouvidos por meio de entrevistas para que expressem sua visão sobre os atendimentos prestados pelos estudantes, bem como suas avaliações quanto à relação entre os objetivos da IES e os serviços prestados, inclusive quando os serviços possuem convênios com a PMF e com o MS, para que haja avaliação das clínicas e locais onde os atendimentos são efetuados.

Nos processos de reelaboração dos serviços, as mudanças sociais são consideradas, entretanto, a vinculação das atividades com a PMF e com o MS é algo que implica em demora na reorganização dos atendimentos. Os alunos, professores ou outros indivíduos prestadores de serviços são instruídos para atender ao público-alvo, pois essa intenção é expressa nos projetos políticos -pedagógicos de todos os cursos. Ainda, a partir das diretrizes curriculares, é identificado o perfil dos egressos que serão formados. Os egressos devem estar capacitados no atendimentoàs demandas da população, compreendendo que devem articular não apenas os atendimentos de saúde, mas devem também ser capazes de 
trabalhar com questões de saneamento, equipamentos e estrutura das unidades de saúde.

Algumas ações educacionais sobre o uso consciente dos insumos durante a prestação de serviços são realizadas. Com a comunidade, isso é realizado principalmente na comunidade do Dendê, próxima à sede da IES. Nesta localidade, existem pessoas que vivem em áreas de proteção ambiental e precisam saber como os resíduos sólidos devem ser destinados. Além disso, existem ações educacionais que são relacionadas às unidades de atuação dos alunos e professores, dependendo das características locais. Estas ações podem ser desenvolvidas em associações de bairros ou associações comerciais. Ainda, há uma disciplina específica para educação ambiental e aspectos sobre sustentabilidade, denominada Universidade, Saúde e Sociedade, integrando alunos iniciantes dos oito cursos. No ambiente estudantil, algumas campanhas são realizadas, como para a utilização eficiente de energia, lixo e material de trabalho que podem gerar resíduos sólidos, bem como o lixo hospitalar. Deste modo, quando o alunado estiver no ambiente real de trabalho, por ter participado das disciplinas educativas para atuação nas comunidades e das campanhas no ambiente da universidade, conseguirá promover ações individuais em suas áreas de atuação, sendo agentes de mudança, conservação e preservação.

No que diz respeito ao direcionamento para desenvolvimento econômico local, embora haja a formação de pessoas para diversas áreas, o núcleo de saúde não tem esse objetivo, tendo suas atividades de ensino, pesquisa e extensão voltadas apenas para a formação dos alunos. Os colaboradores são desenvolvidos por meio de cursos e capacitações, bem como os colaboradores das outras organizações que trabalham em parceria com o NAMI, como os servidores das unidades de saúde do município. Todos os colaboradores, seja da IES ou das unidades de saúde, são envolvidos no planejamento das atividades ligadas aos serviços prestados e todas as informações obtidas durante a execução dos serviços prestados são verificadas para que sejam utilizadas na redefinição do modo como a universidade atua, implicando em processos de melhoria contínua. 


\subsection{Caso 2: IES pública estadual}

A IES pública possui o Centro de Ciências da Saúde (CCS), localizado em Fortaleza-CE, dispondo de cinco cursos em nível de graduação: ciências biológicas, educação física, enfermagem, medicina e nutrição. $\mathrm{O}$ atendimento a comunidade local é realizado por alunos e professores por meio de projetos de extensão, estágios e residências médicas. Parte significativa dos projetos de extensão tem como foco a saúde da família ou de jovens, considerando aspectos relacionados a esportes e prevenção de doenças, como as sexualmente transmissíveis. Não há no website qualquer informação sobre laboratórios, hospitais ou centros de atendimento. As informações dispostas posteriormente foram coletadas mediante entrevista.

As consultas à população para identificação das suas necessidades são realizadas pelas Secretarias Municipal e Estadual de saúde e as informações são repassadas a IES. A IES é responsável pelo atendimento nas regiões IV e V da cidade de Fortaleza-CE, compreendendo 37 bairros e aproximadamente 875 mil habitantes. Não foi informada a quantidade de unidades de saúde contempladas pelos serviços de saúde da IES.

$\mathrm{O}$ atendimento de saúde não tem por objetivo ser fonte de vantagem competitiva, não havendo nenhuma preocupação com competição ou melhoria dos serviços em relação às universidades concorrentes. O único momento em que há atenção à competitividade ocorre na divulgação das notas do Exame Nacional de Desempenho de Estudantes (ENADE). Segundo a gestora entrevistada, algo que pode ser interpretado como diferencial competitivo é o contato direto e constante com o SUS, implicando na vivência real do alunado com sua futura rotina de trabalho quando estes se tornarem profissionais.

Não existem procedimentos formais para verificar a eficácia dos serviços prestados. No entanto, durante as prestações de serviços são coletadas informações de modo informal sobre as demanda sociais e a própria prestação do serviço, implicando na intervenção direta da IES sobre sua atuação, mesmo que isso não seja direcionado ao planejamento das atividades. Além disso, a percepção dos usuários é conhecida mediante o acolhimento da população local que utiliza os serviços nas unidades de saúde. 
A IES não dispõe de hospital próprio, realizando seus atendimentos na rede de saúde, principalmente na rede estadual. Esse fato acarreta na visualização de um "mundo real" para o aluno, não havendo engessamento da estrutura curricular da universidade em decorrência de uma unidade hospitalar. Não são feitas redefinições ou replanejamento dos serviços mediante coleta formal de informações.

Considerando as características do público-alvo atendido, os alunos, professores e outros colaboradores são instruídos para atendê-los. Os cursos de enfermagem, nutrição, ciências biológicas, educação física e medicina, que são aqueles ligados ao centro de ciências da saúde, têm atividade teórico-prática desde o primeiro semestre. No entanto, além destes, outros cursos, que também tem alguma vinculação a atividade de saúde, que são serviço social, psicologia e medicina veterinária, embora este último apenas nas áreas com vinculação a saúde humana, também iniciam suas atividades pela atenção primária do SUS. A atenção primária é o primeiro contato dos alunos com a área de saúde, porém, gradualmente os alunos são expostos ao convívio com ambiente hospitalar, até o momento em que devem cursar o estágio obrigatório, disciplina com atividades plenamente práticas. Foi relatada a importância de que os professores atuem na universidade e nos hospitais como médicos do próprio estado, possibilitando o acesso a informações que abrangem as reais necessidades da população e auxiliem a formação curricular dos alunos. Além disso, há produção de material dos alunos e professores para a rede pública de saúde.

A IES realiza modos distintos de parcerias com a rede pública, ofertando os serviços dos alunos e professores, bem como com cursos e capacitações para os colaboradores das unidades de saúde. Sempre que o SUS precisa de capacidade física instalada procura a universidade. Nessas parcerias são instituídos projetos de pesquisa em favor da demanda do Estado ou Município, embora haja menor incidência de parcerias com este último.

Existem ações educacionais transversais sobre uso de insumos e sustentabilidade durante os atendimentos, estando estas inseridas nas disciplinas. Questões como lixo e água estão presentes nos diversos conteúdos curriculares dos cursos ligados a área da saúde. Porém, nas unidades de saúde, a estrutura física, em muitos casos, 
é precária, dificultando a atuação da IES em mostrar as ações educacionais voltadas aos usos de insumos no ambiente de trabalho.

$\mathrm{O}$ atendimento realizado pelos alunos implica em ampliação de custos, pois como há muita falta de materiais e insumos nas unidades de atendimento, há o fornecimento destes pela IES para que os alunos possam desempenhar suas atividades, mesmo que o abastecimento seja de responsabilidade do Estado ou Prefeitura.

A inserção dos alunos no ambiente de trabalho, mediante supervisão dos professores e trabalho conjunto aos colaboradores das unidades de saúde, se configura como principal meio de desenvolvimento do aprendizado e da sua autonomia enquanto profissional. Existem problemas no desenvolvimento dos professores devido às precariedades da própria rede pública de ensino, pois alguns professores estendem seu trabalho de supervisão à atuação nas unidades de saúde, sendo incorporados indevidamente às rotinas de trabalho locais. Este aspecto confronta os dispositivos legais estabelecidos pela IES, pois amplia a atuação dos docentes além do previsto em seus planos de trabalho. Considerando estes aspectos, os serviços prestados não podem ser considerados como promovedores do desenvolvimento econômico local, mesmo que haja aprovação de alunos em concursos públicos, outros processos seletivos e inserção no mercado de trabalho, conforme a entrevistada, em número superior ao de outras instituições.

\section{ANÁlise comparativa}

Os casos analisados diferenciam-se pela natureza das pessoas jurídicas, sendo o Caso A uma organização privada e o Caso B uma organização pública estadual. Verificou-se a existência de contrastes entre as estratégias adotadas e os serviços prestados pelas IES analisadas quanto aos processos que têm alguma relação com a CSV. O Quadro 4 mostra que a IES privada atendeu mais níveis e etapas de CSV do que a IES pública estadual. 
Quadro 4 - Quadro de análise dos atendimentos aos níveis e etapas de CSV

\begin{tabular}{|c|c|c|c|}
\hline \multirow[t]{2}{*}{ Níveis } & \multirow[t]{2}{*}{ Etapas } & \multicolumn{2}{|l|}{ Casos } \\
\hline & & $\mathrm{A}$ & B \\
\hline \multirow{4}{*}{$\begin{array}{l}\text { 1. Reava- } \\
\text { liação de } \\
\text { produtos e } \\
\text { serviços }\end{array}$} & 1. Identificação das questões alvo & Total & Total \\
\hline & 2. Fazer o caso do negócio & Total & $\begin{array}{l}\begin{array}{l}\text { Não } \\
\text { atendeu }\end{array} \\
\end{array}$ \\
\hline & 3. Acompanhamento do progresso & Total & $\begin{array}{l}\text { Não } \\
\text { atendeu }\end{array}$ \\
\hline & 4. Avaliação dos resultados & Parcial & Parcial \\
\hline \multirow{4}{*}{$\begin{array}{l}\text { 2. Redefini- } \\
\text { ção na cadeia } \\
\text { de valor }\end{array}$} & 1. Identificação das questões alvo & Total & Total \\
\hline & 2. Fazer o caso do negócio & Parcial & Parcial \\
\hline & 3. Acompanhamento do progresso & Parcial & $\begin{array}{l}\text { Não } \\
\text { atendeu }\end{array}$ \\
\hline & 4. Avaliação dos resultados & Total & Parcial \\
\hline \multirow{4}{*}{$\begin{array}{l}\text { 3. Suporte } \\
\text { ao desenvol- } \\
\text { vimento de } \\
\text { clusters locais }\end{array}$} & 1. Identificação das questões alvo & Parcial & $\begin{array}{l}\text { Não } \\
\text { atendeu }\end{array}$ \\
\hline & 2. Fazer o caso do negócio & Parcial & $\begin{array}{l}\text { Não } \\
\text { atendeu }\end{array}$ \\
\hline & 3. Acompanhamento do progresso & Total & $\begin{array}{l}\text { Não } \\
\text { atendeu }\end{array}$ \\
\hline & 4. Avaliação dos resultados & Total & $\begin{array}{l}\text { Não } \\
\text { atendeu }\end{array}$ \\
\hline
\end{tabular}

Fonte: Elaborado pelos autores com base nos dados da pesquisa (2015).

No primeiro nível, reavaliação de produtos e serviços, apenas a etapa de identificação das questões alvo foi atendida plenamente pelas duas IES. Esta etapa não é feita diretamente por nenhuma das universidades, sendo realizada pela Secretaria Municipal de Saúde da PMF e pela Secretaria Estadual de Saúde do Estado do Ceará. A identificação das questões alvo em relação a reavaliação de produtos e serviços é aproveitada para o replanejamento dos serviços prestados pela IES privada, não havendo qualquer forma de processo similar para os serviços da IES pública estadual. Isto se torna mais evidente quando se verifica que as outras etapas do mesmo nível não são atendidas pela IES pública estadual. Em contrapartida, a IES privada utiliza para redefinir suas estratégias e serviços, elaboran- 
do e aplicando mecanismos de avaliação da eficácia dos resultados que ultrapassam os limites do que é usualmente solicitado pelas entidades públicas, como a avaliação de Kirkpatrick.

Os resultados do segundo nível possuem avaliações mais homogêneas entre as IES quando comparados aos outros níveis. A concepção da redefinição na cadeia de valor, para os dois casos analisados, consistiu em atribuir às características dos serviços elementos que podem atender as demandas sociais do público-alvo, instruindo alunos e corpo docente para desempenhar suas funções. No entanto, a IES pública estadual utiliza mecanismos informais para isto, questionando as pessoas atendidas quanto à qualidade dos serviços prestados, enquanto a IES privada possui mecanismos institucionalizados para isto. Ademais, o acompanhamento do progresso da redefinição na cadeia de valor não é realizado pelo IES pública estadual. Algo que se destaca nos dois casos estudados é o fato dos serviços prestados não serem fator de minimização de custos.

O suporte ao desenvolvimento de clusters locais, terceiro nível, compreende o apoio dado ao fomento do empreendedorismo local e estímulo ao desenvolvimento da economia local por meio de um mercado justo. A IES privada, embora não tenha o objetivo declarado de desenvolver economicamente o local onde atua, dispõe de salas em seu Núcleo Médico de Atenção Integrada para que profissionais liberais da área da saúde possam atuar, inclusive contando com a mediação de planos de saúde.Esta estratégia pode ser compreendida como algo relevante para o fomento do desenvolvimento econômico local, embora não seja declaradamente pautado em uma forma de mercado justo. Enquanto a IES pública não contempla este nível, pois suas estratégias e serviços não tem por intuito o desenvolvimento da economia local.

\subsection{DISCUSSÃo}

Os resultados verificados mediante análise do atendimento dos níveis e etapas não apresentaram comportamento gradual totalmente similar ao disposto por Porter e Kramer (2011), Porter et al. (2012) e Spitzeck e Chapman (2012). A IES privada, mesmo atendendo aos três níveis, não atende completamente a todas as etapas, algo que não torna a empresa incapaz ou ineficiente em criar e compartilhar 
valor. As características de identificação das demandas sociais e o planejamento criado para execução das atividades apresentaram sinergia, bem como as ações de acompanhamento do progresso das atividades com a avaliação dos resultados. O não atendimento pleno aos níveis e etapas pode conferir a falta de refinamento das estratégias de CSV, conforme Porter et al., 2012. Em contrapartida, a IES pública, tem suas ações "engessadas" pelos aspectos institucionais normativos, estando impossibilitada por entraves burocráticos para criar mecanismos de planejamento, acompanhamento de progresso e avaliação dos resultados.

Destaca-se que o Caso A apresentou características distintas na sua forma de compartilhar valor quando comparado aos casos apresentados por Aravossis e Pavloupoulou (2013) e Camilleri (2012). A IES privada cria e compartilha valor não apenas pelos programas de CSR, mas também por meio de sua atividade fim, o próprio ensino em conjunto com a prestação dos serviços em saúde, constituindo nisso uma das vantagens competitivas do negócio e financiamento das atividades, porém sem se transformar em empreendimento social, conforme os casos analisados por Christilieb (2012). Além disso, o primeiro nível de CSV, para ambos os casos analisados, não tem como característica a identificação direta das necessidades do público-alvo, sendo isto feito pelos parceiros públicos, o município e o estado.

A identificação das necessidades do público-alvo feita de forma indireta implica na participação de outros atores no diálogo com as IES, promovendo um exercício comunitário na concepção da política de serviços das organizações, como o disposto por Morosini (2008). Outro elemento que reforça a participação dos stakeholders externos as IES na formulação de estratégias e serviços é a implementação da Avaliação de Kirkpatrick pelo Caso A, que considera, além da comunidade acadêmica, os benefícios gerados para a sociedade, estando em conformidade com os procedimentos descritos por Triviños, Sirhan, Moore e Montero (2011, 2014), embora haja distinção na ordem dos níveis trabalhados entre a IES.

Verificou-se que os serviços prestados pelos dois casos analisados não tem características dessemelhantes às funções fundamentaisdos cursos da área de saúde, enquadrando suas atividades em um ciclo contínuo de prestação de serviços, conforme Drucker (1996). 
Essa característica de continuidade em ciclo denota o exercício de ações baseadas em CSR, porém sem natureza filantrópica, pois o atendimento dos alunos e docentes faz parte das políticas das IES, como se refere Todorov (2005). A transcendência das ações fundamentadas no voluntariado beneficia tanto as organizações quanto a comunidade em seu entorno, conforme Vallaeys (2006). Entretanto, apenas a IES privada consegue beneficiar a comunidade em seu entorno ao ponto de ter o desenvolvimento de clusters baseados em alianças econômicas com profissionais liberais da área de saúde e planos de saúde, se diferenciando dos clustersformados nos casos estudados por Mena e Zelaya (2013), que se formam como alianças entre organizações da própria comunidade educacional.

\section{Conclusão}

Os casos estudados demonstram que a criação e compartilhamento de valor ocorrem por meio do envolvimento entre o corpo docente, corpo técnico, corpo discente e governo estadual na prestação de serviços e elaboração de estratégias que contemplam os níveis e etapas de CSV, embora esta conclusão seja resultante apenas da análise na IES privada. Pois, os dois casos estudados apresentaram comportamentos distintos sob a perspectiva da criação e compartilhamento de valor.

O Caso A, organização privada, cria e compartilha valor nos níveis de reavaliação de produtos e serviços, redefinição na cadeia de valor e suporte ao desenvolvimento de clusters locais. Além disso, o caso contempla as quatro etapas, mesmo que parcialmente, para cada nível de CSV esuas atividades se apresentam como vantagem competitiva, mesmo que não haja pretensão declarada disto.

O Caso B, organização pública estadual, não cria ou compartilha valor, pois não atende totalmente nenhum nível de CSV. Verificou-se que os entraves preponderantes para isto podem ser originados na sua natureza jurídica pública. A identificação das necessidades do público-alvo nos dois primeiros níveis foramas etapas com melhores avaliações. Em contrapartida, nenhum instrumento formal de acompanhamento do progresso das atividades, avaliação ou planejamento é aplicado ou está em fase de implementação. Foi verificada apenas um modo informal de acompanhamento do progresso e avaliação 
das atividades para todos os níveis, sendo isto feito por meio de feedback dos coordenadores das unidades de saúde e pelo acolhimento dado pelos usuários dos serviços aos alunos e professores.

Embora a análise demonstre resultados diferentes para as IES, não é possível inferir que a natureza jurídica pública seja o fator preponderante para não haver criação e compartilhamento de valor em qualquer organização, pois o método do estudo de caso implica nesta limitação. Assim, e por fim, esta pesquisa contribui para os trabalhos de comparação da aplicação do modelo de CSV em organizações públicas e privadas, e encerra inferindo se o modelo de CSV pode ser aplicável às organizações públicas, recomendando também a continuidade do estudo de campo nas universidades públicas e privadas brasileiras, em outros setores públicos e privadosque não o de educação em saúde, bem como a criação de métodos quantitativos de avaliação de CSV.

\section{REFERÊNCIAS}

BARDIN, L. Análise de conteúdo. Lisboa: Edições, 2009.

BESCHORNER, T.; HAJDUK, T. Creating Shared Value. A Fundamental Critique. In: Creating Shared Value-Concepts, Experience, Criticism. Springer International Publishing, 2017. p. 27-37.

BRASIL. Lei n⿳o. 10.861, de 14 de abril de 2004. Institui o Sistema Nacional de Avaliação da Educação Superior - Sinaes - e dá outras providências. Diário Oficial [da República Federativa do Brasil], Brasília, DF, n. 72, p. 3-4, 15 abr. 2004.

CAMILLERI, M. A. Creating shared value through strategic CSR in tourism. 2012. $455 \mathrm{f}$. Thesis (PhD in Management) - Business School Program, University of Edinburgh, Edinburgh, 2012.

CAMPOS, F. E. et al. O SUS como escola: a responsabilidade social com a atenção à saúde da população e com a aprendizagem dos futuros profissionais de saúde. Revista Brasileira de Educação Médica, Rio de Janeiro, Associação Brasileira de Educação Médica, v. 33, n. 4, p. 513-514, 2009.

CARROLL, A. B. A commentary and an overview of key questions on corporate social performance measurement. Business \& Society, v. 39, n. 4, p. 466-478, 2000

CRANE, A. et al. Contesting the value of "creating shared value". California Management Review, Berkeley, v. 56, n. 2, p. 130-153, 2014.

DRUCKER, P. F. O novo papel da administração. São Paulo: Nova Cultural, 1986.

FILENGA, D.; VIEIRA, A. M. Relações organizacionais no contexto de uma cooperativa médica: adoção e resistência quanto ao uso de TI. Revista de Administração de Roraima RARR, v. 5, p. 263-284, 2015. 
FLICK, U. Uma introdução à pesquisa qualitativa. Porto Alegre: Bookman, 2004.

LOMBARDO, Rosetta; D'ORIO, Giovanni. Corporate and State Social Responsibility: A LongTerm Perspective. Modern Economy, v. 3, n. 01, p. 91, 2012.

MAIA, L. F. R. B. ; XIMENES, V. M. ; OLIVEIRA, J. D. ; FIRMEZA, J. S. Prioridades axiológicas como fatores explicativos do comportamento de cidadania organizacional no cenário da farmácia de um hospital universitário. XXXII Encontro Nacional de Pós-Graduação e Pesquisa em Administração, Rio de janeiro, 2008.

MARTINS FILHO, J. Em defesa das Universidades. Brasília: Ed. do Conselho de Reitores das Universidades Brasileiras, 1997.

MEDEIROS, H. et al. Criação de valor compartilhado: um novo olhar sobre as organizações?. Revista Brasileira de Administração Científica, v. 7, n. 1, p. 217-229, 2016.

MOROSINI, M. C. Qualidade na educação superior: tendência do século XXI. In: TRAVESINI, Clarice; EGBERT, Eddla; PERES, Eliane; BONIN, Iara. Trajetórias e processos de ensinar e aprender: práticas e didática. Porto Alegre: EDIPUCRS, 2008.

NIKOLOVA, N.; ANDERSEN, L. Creating Shared Value Through Service-Learning in Management Education. Journal of Management Education, p. 1052562917715883, 2017.

PITTS, A. Private sector relationships to ODA: measuring shared values. In: KAPA Winter Conference - National Competitiveness: diagnosis and policy prescriptions, 01, Daegu, 2014. Disponível em: <http://www.kapa21.or.kr/data/data_download.php?did=7066>. Acessoem: 16 maio 2015.

PORTER, M. E. Clusters and Competition: New Agendas for Companies, Governments, and Institutions. In: On Competition. Boston: Harvard Business School Press, 1998.

PORTER, M. E. et al. Measuring shared value-how to unlock value by linking business and social results. Foundation Strategy Report, p. 1-20, 2012.

PORTER, M. E.; KRAMER, M. R. Creating Shared Value.How to reinvent capitalism and unleash a new wave of innovation and growth. Harvard Business Review, Harvard University, Boston, p. 1-17, jan./fev. 2011.

PORTER, M. E.; KRAMER, M. R. Strategy and society: the thin line between competitive advantage and corporate social responsibility. Harvard Business Review, Harvard University, Boston, v. 1, n. 1, p. 1-15, 2006.

PORTER, M. E.; KRAMER, M. R. The competitive advantage of corporate philanthropy. Harvard Business Review, Harvard University, Boston, v. 80, n. 12, p. 56-68, 2002.

PRAHALAD, C. K.; HART, S. L.The fortune at the bottom of the pyramid. Strategy+Business, v. 26, p. 1-15, 2002.

ROCCHI, M.; FERRERO, I. Shared Value in Finance: Revisiting Shared Value in Light of the Person-Centered Approach, 2014. Disponível em: <http://www.unav.edu/documents/10174/6546776/wp7.pdf>. Acesso em: 25 maio 2015.

SPITZECK, H.; CHAPMAN, S. Creating shared value as a differentiation strategy -the example of BASF in Brazil. Corporate Governance: The International Journal Of Business In Society, Emerald Group Publishing, Bingley, v. 12, n. 4, p. 499-513, 2012. 
TODOROV, J. C. O conceito de responsabilidade social nos estabelecimentos de ensino superior. Revista Estudos, Pontifícia Universidade Católica de Goiás, Goiânia, v. 23, p. 41-46, 2005. TRIVIÑOS, X. et al. Experiencias en la implementación de un programa de formación en docencia para profesores de medicina en una universidad de Chile. Revista Peruana de Medicina Experimental y Salud Publica, Instituto Nacional de Salud, Lima, v. 31, n. 3, p. 417-423, 2014.

TRIVIÑOS, X. et al. Impacto de un programa de formación en docencia en una escuela de medicina. Revista Médica De Chile, Sociedad Médica de Santiago, Santiago, v. 139, n. 11, p. 1508-1515, 2011.

VALLAEYS, F. Que significa responsabilidade social universitária. Revista Estudos, Pontifícia Universidade Católica de Goiás, Goiânia, n. 36, p. 37, 2006.

WÓJCIK, P. How Creating Shared Value Differs From Corporate SocialResponsibility. Journal of Management and Business Administration, v. 24, n. 2, p. 32-55, 2016.

YIN, R. K. Estudo de Caso: Planejamento e método. Porto Alegre: Bookman, 2001.

Recebido em: 3-2-2018

Aprovado em: 4-12-2018

Avaliado pelo sistema double blind review.

Editor: Coordenação do PPGA/UMESP

Disponível em http://mjs.metodista.br/index.php/roc 